\title{
Comparison of Plasma Oxidative Status Biomarkers in Neonatal Dairy Calves during Summer and Fall Seasons
}

\author{
Munashe Chigerwe*, April D Beck, Sharon S Kim and David M Coons \\ Department of Medicine and Epidemiology, University of California-Davis, Davis, CA, USA
}

\begin{abstract}
Heat stress impairs normal physiology and behavior in dairy calves. Oxidative status can be evaluated using plasma markers of oxidative stress. Studies on effects of heat stress on oxidative status as a result of exposure to summer weather in dairy calves are lacking. The purpose of this study was to compare the activity or concentrations of plasma markers of oxidative stress of dairy calves raised in the summer, compared to those raised in the fall in a single calendar year. Thirty-four Jersey calves born in summer and 33 born in fall, aged 24-48 hours age were enrolled. Plasma glutathione peroxidase (GSH-Px), superoxide dismutase (SOD) activities, and concentrations of thiobarbituric acid reactive substances (TBARS) were determined. Temperature humidity index was also determined. Mean activities of GSH-Px and SOD were higher for calves born and raised in summer, compared to calves born in fall. Concentrations of TBARS were not consistently different in calves born and raised in summer, compared to calves born in fall. Study results suggest condition of oxidative stress of calves born and raised in summer compared to calves born in fall. Results of this study suggest that plasma GSH-Px and SOD may be useful in monitoring calves for evidence of oxidative stress. Potential application from the results of this study on farms contracted to raise calves is to objectively monitor calves' oxidative status upon arrival from the farm of origin, or at weaning when calves are comming led in larger groups during different seasons of year, and to adjust housing conditions accordingly.
\end{abstract}

Keywords: Plasma; Oxidative status; Calf; Dairy; Heat stress

\section{Introduction}

Oxidative stress results when reactive forms of oxygen are produced faster than they can be safely neutralized by antioxidant physiologic mechanisms [1]. Increased production of free radicals and reactive oxygen species, and decreased antioxidant defense mechanisms leads to damage of macromolecules and disruption of normal metabolism during oxidative stress [2]. Consequently, oxidative stress can predispose or lead to disease in cattle [3]. Biomarkers in plasma, and/or erythrocytes are used to evaluate oxidative stress in various animal species [4]. In adult cattle, biomarkers to assess oxidative stress include plasma or erythrocyte glutathione peroxidase, reactive oxygen metabolites, intracellular and plasma thiols, superoxide dismutase and thiobarbituric acid reactive substances [5].

Several factors have been reported to induce oxidative stress in livestock species. Oxidative stress has been associated with the process of birth in calves [6], and piglets [7,8]. The transition period (3 weeks before parturition to 3 weeks after parturition) [9], also has been associated with oxidative stress resulting in periparturient metabolic disorders in cattle [3,9]. Elevated activities of erythrocyte superoxide dismutase, erythrocyte and plasma glutathione peroxidase, and elevated levels of intracellular thiols and thiobarbituric acid reactive substances have been reported in adult dairy cattle exposed to heat stress in summer, compared to adult dairy cattle exposed to spring weather conditions [5].

It has been reported that calves have a narrower thermal neutral zone compared to adult cattle [10], and heat stress occurred at temperatures greater than $32^{\circ} \mathrm{C}$ at $60 \%$ humidity $[11,12]$. When the level at which the calf's total heat gain exceeded the calf's ability to lose heat, heat stress developed, resulting in impaired physiology and behavior in the calf [11]. Long-term effects of heat stress in calves included reduced productivity, as a result of increased age at calving [13].

To the authors' knowledge, studies on the effects of heat stress on oxidative result status in dairy calves are lacking. We hypothesized that dairy calves exposed to heat stress, as a result of the hot season (summer), will experience oxidative stress, as indicated by the increase in biomarkers of oxidative status compared to calves exposed to the weather considered thermoneutral (fall). The objectives of this study was to compare activity and concentrations of plasma markers of oxidative stress of dairy calves born and raised in summer to those born and raised in fall in a single calendar year. The results of the study have potential application in monitoring oxidative status of preweaned calves, and adjusting housing and rearing conditions during hot environmental period's conditions of the year.

\section{Materials and Methods}

The study was approved by the University of California, Davis, Institutional Animal Care and Use Committee. Data indicating the relative risk of calves born and raised in summer to have elevated levels of plasma oxidative markers of stress compared to calves born and raised in fall were not available, and hence a conservative relative risk of 2 was assumed. Thus, the sample size was based on a $\beta=0.80$ (power), $P=0.05$ for a two sided test, and a relative risk of 2 for elevated levels of plasma oxidative markers of stress for calves born in summer, compared to calves born in fall [14]. The minimum sample size required for each group was 29 calves. To account for

*Corresponding author: Munashe Chigerwe, Department of Medicine and Epidemiology, University of California-Davis, One Shields Avenue, Davis, CA 95616, USA, Tel: +1 (530)-752-8235; Fax: +1 (530)-752-0414; E-mail: mchigerwe@ucdavis.edu

Received March 17, 2013; Accepted April 22, 2013; Published April 24, 2013

Citation: Chigerwe M, Beck AD, Kim SS, Coons DM (2013) Comparison of Plasma Oxidative Status Biomarkers in Neonatal Dairy Calves during Summer and Fall Seasons. J Veterinar Sci Technol S11: 005. doi:10.4172/2157-7579.S11-006

Copyright: (c) 2013 Chigerwe M, et al. This is an open-access article distributed under the terms of the Creative Commons Attribution License, which permits unrestricted use, distribution, and reproduction in any medium, provided the original author and source are credited. 
$10 \%$ drop out of calves due to missed sample collection, at least 32 calves were enrolled in each group.

\section{Animals}

A total of sixty-seven, 1-3 day old Jersey heifer calves were enrolled. Thirty-four calves were enrolled in summer, (July-August, 2011), and 33 calves were enrolled in fall 2011 (October-November, 2011). All calves enrolled were from a single herd located on a calf-raising farm, in Chowchilla, Madera County, California. The calf-raising farm was contracted by the farm of origin, in Hilmar, Merced County, California, to raise the dairy calves up to 4 months of age. The distance between the two farms by road was approximately $80 \mathrm{~km}$ ( 50 miles). All calves were fed 6 liters of colostrum ( 3 liters twice) within 24 hours at the farm of origin. The calves were delivered by road transportation to the farm of study at 24-48 hours of age. On arrival to the calf-raising farm, calves were raised singly in wooden calf hutches raised above ground. The roof, sidewalls and the floor of the hutches had spaces approximately 3-4 $\mathrm{cm}$ wide between the wooden planks. The hutches allowed noseto-nose contact between neighboring calves. Upon arrival to the farm of study, calves were fed 2 liters of milk replacer twice daily and 0.6 $\mathrm{kg}$ of commercial concentrate diet recommended for dairy calves and water available ad libitum. Calves were weaned from milk replacer at 8-10 weeks of age and housed in group pens of 30-40 calves. The herdsmen monitored calves twice daily for signs of clinical disease, and events of clinical disease were recorded. The major clinical signs considered consistent with clinical disease recorded by the herdsmen were anorexia, diarrhea and coughing. All calves enrolled experienced similar management conditions. At 4 months of age, the calves were transported back to the farm of origin.

For purposes of this study, summer season included the months of June, July and August. Fall season included the months of September, October and November. The initial blood collection was performed in all the enrolled calves at 24-72 hours of age (week 1), and once every week, thereafter for 4 weeks (week 2 -week 5 ) by jugular venipuncture. Blood $(10 \mathrm{ml})$ was collected using vacutainer needles (Becton Dickson, Franklin Lakes, NJ, USA) into vacutainer blood collection tubes containing lithium heparin as an anticoagulant (Becton Dickson, Franklin Lakes, NJ, USA). At the time of each blood collection, rectal temperature of each calf was determined using a rectal thermometer (Medline, Mundelein, IL, USA). In order to calculate the temperaturehumidity index (THI), the hourly temperature and humidity of the air was obtained from the local weather station (KCACHOWC3 Station, Chowchilla, CA, USA). The THI $\left(\mathrm{T}_{\mathrm{d}}^{\circ} \mathrm{F}\right)$ was calculated based on ambient temperature and relative humidity, using a previously reported method [15]. Blood samples were transported on ice to the laboratory within 3 hours after collection.

Analysis of effects of morbidity (based on recorded morbidity events and treatment records) on the activity of the plasma oxidative stress biomarkers in calves was not analyzed, because a small number of calves were reported to have been sick by the herdsman/women in this group of calves ( 3 calves in summer and 4 calves in fall).

\section{Laboratory analysis}

Blood was centrifuged to harvest plasma using a centrifuge at 4500 rpm for 5 minutes at $4^{\circ} \mathrm{C}$. Plasma samples were stored at $-20^{\circ} \mathrm{C}$, until determination of plasma oxidative stress biomarkers. Plasma samples were analyzed within 6 months after collection. Plasma glutathione peroxidase (GSH-Px) activity was determined by a kinetic method, using a commercial assay kit (Cayman Chemical Company, catalog number 703102, Ann Arbor, MI, USA), and was expressed in nmol/ $\mathrm{min} / \mathrm{ml}$. GSH-Px activity was determined by measuring mean rate of catalysis based on the decrease in absorbance at $340 \mathrm{~nm}$ using a plate reader (Powerwave HT microplate reader, Biotek Instruments Inc, Winooski, VT). Plasma superoxide dismutase (SOD) activity was determined by an endpoint assay using a commercial assay kit (Cayman Chemical Company, catalog number, 706002, Ann Arbor, MI, USA), and expressed in units/ml. Plasma thiobarbituric acid reactive substances (TBARS) concentrations were determined by an endpoint assay using a commercial kit (Cayman Chemical Company, catalog number 10009055, Ann Arbor, MI, USA), and expressed in $\mathrm{nmol} / \mathrm{ml}$. The activity of SOD and concentrations of TBARS were determined colorimetrically at $450 \mathrm{~nm}$ as an end-point assay using a plate reader (Powerwave HT microplate reader, Biotek Instruments Inc, Winooski, VT).

\section{Data analysis}

Data analysis diagnostics were performed to assess normality of the variables, using the Shapiro-Wilk test. Comparison of mean age at enrollment and mean rectal temperatures between calves born in summer and fall were analyzed using a Student'st-test for independent groups. Activities of the GSH-Px and SOD or concentrations of TBARS were analyzed using repeated measures of ANOVA with group (summer or fall born calves) and age of calves (week 1 through week 5), as independent variables. When differences between the activities of GSH-Px, SOD, or the concentrations of TBARS were detected between the two groups of calves born in summer and fall, mean separation techniques (Duncan multiple range test), with adjustment for multiple comparisons using the Bonferroni adjustment was used. Interactions between the season (summer or fall) and activities of the enzymes at different ages (week 1-week 5) were also investigated. For all analyses, $\mathrm{P}<0.05$ was considered significant. For all analyses, commercial statistical software was used (SAS Version 9.3, Cary, NC, USA).

\section{Results}

Data diagnostics indicated that the variables were normally distributed, hence means are reported here. Mean \pm SEM age for calves enrolled in summer and fall was $2.14 \pm 0.12$ and $2.76 \pm 0.17$ days, respectively at the time of enrollment. There was no difference in the age of the calves at enrollment $(\mathrm{P}=0.680)$. The daily mean THI \pm SEM $\left({ }^{\circ} \mathrm{F}\right)$ for summer and fall was $71.3 \pm 1.2\left(21.8 \pm 0.5^{\circ} \mathrm{C}\right)$ and $65.3 \pm 1.4(18.5$ $\pm 0.3^{\circ} \mathrm{C}$ ), respectively. The mean daily THI was higher in the summer season compared to the fall season $(\mathrm{P}=0.041)$. Mean \pm SEM $\left({ }^{\circ} \mathrm{C}\right)$ for rectal temperatures for calves born in summer and fall were $38.6 \pm 0.2$ and $38.6 \pm 0.1$, respectively. There was no difference in the mean rectal temperatures for calves born and raised in summer compared to calves born and raised in fall $(\mathrm{P}=0.773)$.

Mean \pm SEM for all 5 weeks activity of GSP-Px for calves born in summer $(91.7 \pm 3.0)$ was higher $(\mathrm{P}<0.001)$, compared to calves born in fall (47 \pm 1.3$)$. Calves born in summer had higher GSH-Px activities at week $1(\mathrm{P}=0.0002)$, week $2(\mathrm{P}<0.0001)$, week $3(\mathrm{P}<0.0001)$ and week 5 $(\mathrm{P}<0.0001)$ of sample collection compared to calves born in fall. There was no difference in activity of GSH-Px at week $4(\mathrm{P}=0.10)$ of sample collection between calves born in summer and fall. Interactions between group (summer or fall) and age (time) were significant $(\mathrm{P}<0.001)$ for GSH-Px activities.

Mean \pm SEM activity for all 5 weeks of SOD for calves born in summer $12.0 \pm 0.5$ was higher $(\mathrm{P}<0.001)$, compared to calves born in fall $(9.5 \pm 0.2)$. There was no difference in SOD activity at week 1 


\begin{tabular}{|c|c|c|c|c|c|c|}
\hline \multicolumn{7}{|c|}{ Week at sample collection } \\
\hline & & Week 1 & Week 2 & Week 3 & Week 4 & Week 5 \\
\hline \multirow[b]{2}{*}{ GSH-Px } & Summer & $98.7 \pm 15.0^{\mathrm{a}}$ & $140.5 \pm 6.3^{a}$ & $70.5 \pm 5.5^{\mathrm{a}}$ & $74.9 \pm 3.9$ & $70.4 \pm 4.8^{a}$ \\
\hline & Fall & $41.6 \pm 3.3^{b}$ & $52.2 \pm 3.9^{b}$ & $36.4 \pm 2.4^{b}$ & $65.5 \pm 4.0$ & $39.2 \pm 2.6^{b}$ \\
\hline \multirow[b]{2}{*}{ SOD } & Summer & $9.1 \pm 0.6$ & $9.8 \pm 1.0$ & $11.4 \pm 1.5^{\mathrm{A}}$ & $19.8 \pm 1.0^{\mathrm{a}}$ & $12.6 \pm 1.0^{\mathrm{A}}$ \\
\hline & Fall & $7.7 \pm 0.4$ & $10.1 \pm 1.2$ & $4.0 \pm 0.2^{B}$ & $8.6 \pm 0.9^{b}$ & $18.0 \pm 1.0^{\mathrm{B}}$ \\
\hline \multirow[b]{2}{*}{ TBARS } & Summer & $8.1 \pm 0.6$ & $5.2 \pm 0.5^{A}$ & $7.9 \pm 1.0$ & $4.9 \pm 1.0$ & $7.7 \pm 1.3$ \\
\hline & Fall & $7.5 \pm 0.8$ & $8.5 \pm 1.2^{\mathrm{B}}$ & $6.9 \pm 0.7$ & $4.1 \pm 0.9$ & $6.3 \pm 0.5$ \\
\hline
\end{tabular}

a,b Means within column with different superscripts for each measured parameters are different $(P<0.05)$.

$A, B$ Means within column with different superscripts for each measured parameters are different $(P<0.05)$.

Table 1: Mean \pm SEM for activities of plasma glutathione peroxidase (GSH-Px;nmol/min/ml) and superoxide dismutase (SOD; units/ml), and concentration of thiobarbituric acid reactive substances (TBARS; $\mathrm{nmol} / \mathrm{ml}$ ) in Jersey calves born and raised in summer or fall.

$(\mathrm{P}=0.068)$ and week 2 of age $(\mathrm{P}=0.862)$. The SOD activity was higher in calves born in summer at week $3(\mathrm{P}<0.0001)$ week $4(\mathrm{P}<0.0001)$ of age, but SOD activity for calves born in fall was higher compared to calves born in summer at week 5 of age $(\mathrm{P}=0.0003)$. Interactions between group (summer or fall) and age (time) were significant $(\mathrm{P}<0.001)$ for SOD activities.

Mean for all 5 weeks concentrations of TBARS for calves born in summer $(5.7 \pm 0.3)$ were not different $(\mathrm{P}=0.362)$, compared to calves born in summer $(7.0 \pm 0.5)$. Age of the calf (time) was the only significant variable in determining TBARS activity $(\mathrm{P}=0.0062)$, with the TBARS activity higher in calves born in fall at week 2 of age $(\mathrm{P}=0.028)$. Interactions between group (summer or fall) and age (time) were not significant $(\mathrm{P}=0.109)$ for TBARS concentrations. The activities for GSPPx and SOD and TBARS concentrations for all calves are summarized in table 1.

\section{Discussion}

Mean activity for all 5 weeks of GSH-Px and SOD was consistently higher for calves born and raised in summer, compared to calves born in fall, indicating a condition of oxidative stress of calves born and raised in summer to oxidative stress. Concentrations of TBARS were not consistently higher in calves born and raised in summer, compared to calves born in fall. Higher activities of SOD (week 5) and concentrations of TBARS (week 2) in fall calves compared to summer calves may suggest that other factors other than the environmental temperature may play a role. The results of this study indicate that plasma GSH-Px and SOD may be useful in monitoring calves for evidence of oxidative stress. Based on the results of the study, it can be recommended for farms contracted to raise calves to objectively monitor a calf's oxidative status upon arrival from the farm of origin, and at weaning when calves are commingled in larger groups during different seasons of the year. This assumes that the process of weaning and commingling into groups are potential sources of stress in calves. Results of the oxidative status of the calves may be used to adjust housing conditions, as well as to determine the number of calves to be commingled at weaning. Consequently, the monitoring of oxidative status using GSP-Px and SOD may be use as part of calf welfare monitoring.

A few drawbacks are evident in this study. Only plasma GSH-Px, SOD and TBARS were evaluated. Previous studies have evaluated erythrocyte glutathione peroxidase, malondialdehyde, reactive oxygen metabolites, intracellular and plasma thiols $[5,6]$. The reason for choosing the reported plasmaoxidative biomarkers were based on practical availability of the assays. Thus, we anticipated that if the assays were deemed useful, they would be available to general veterinary practitioners through laboratories. As a result of the potential negative effects on normal physiology and behavior [13], one potential consequence of heat stress in calves could be decreased weight gain. Weaning weights (therefore estimating average daily gain) were not compared in this study, because the age at weaning of calves varied between 8 and 10 weeks. It is also important to note that only GSHPx and SOD activities were elevated, and this may alternatively suggest that oxidative stress may not be of practical importance on this specific farm. The THI reported in this study is comparable to studies performed in adult cows [5], but lower than the studies performed in calves [11]. Additionally, while plasma oxidative markers were assessed in studies performed in adult dairy cows [5], oxidative markers evaluation were not performed in studied performed in calves [11].

Previous studies compared oxidative status between adult dairy cows that calved in spring and summer [5]. In this study, we compared oxidative status in calves born and raised in summer to calves born and raised in fall. We chose fall over spring due to the weather experienced in the geographical county the study was performed, which is characterized by significant rainfall during spring (KCACHOWC3 Station, Chowchilla, CA, USA). As a result of the type of the calf hutches in which the calves were raised (open spaces between the wooden planks), rainfall would have been a significant confounder affecting the oxidative status of the calves. In contrast, little or no rainfall was recorded during summer and fall during the period of study. It should be noted that the cost of the type of calf hutch described here is cost effective compared to plastic hutches. Hence, it is preferred on farms raising large numbers of calves. However, the wooden hutches are more likely to be ineffective at protecting calves from inclement weather conditions. Studies comparing oxidative status of calves raised in differently designed calf hutches are required.

\section{Conclusions}

Activities of GSH-Px and SOD were consistently higher in calves born and raised in summer, compared to those born and raised in fall. The results of this study may serve as background for future studies. The concentrations of TBARS for calves born and raised in summer were not consistently higher, compared to fall calves. Specific future studies will focus on comparing oxidative status of calves raised in wooden hutches, compared to calves raised in plastic hutches during different seasons of the year. The results of such studies will have broader application in monitoring and adjusting calf welfare concerns related to housing and rearing conditions.

\section{References}

1. Sies H (1991) Oxidative stress: from basic research to clinical application. Am J Med 91: 31S-38S.

2. Trevisan M, Browne R, Ram M, Muti P, Freudenheim J, et al. (2001) Correlates of markers of oxidative status in the general population. Am J Epidemiol 154 348-356. 
Citation: Chigerwe M, Beck AD, Kim SS, Coons DM (2013) Comparison of Plasma Oxidative Status Biomarkers in Neonatal Dairy Calves during Summer and Fall Seasons. J Veterinar Sci Technol S11: 005. doi:10.4172/2157-7579.S11-006

3. Miller JK, Brzezinska-Slebodzinska E, Madsen FC (1993) Oxidative stress, antioxidants, and animal function. J Dairy Sci 76: 2812-2823.

4. Passi S, Stancato A, Cocchi M (2001) A monitoring of oxidative stress of ageing-related diseases. Prog Nutr 3: 35-58.

5. Bernabucci U, Ronchi B, Lacetera N, Nardone A (2002) Markers of oxidative status in plasma and erythrocytes of transition dairy cows during hot season. J Dairy Sci 85: 2173-2179.

6. Gaál T, Ribiczeyné-Szabó P, Stadler K, Jakus J, Reiczigel J, et al. (2006) Free radicals, lipid peroxidation and the antioxidant system in the blood of cows and newborn calves around calving. Comp Biochem Physiol B Biochem Mol Biol 143: 391-396.

7. Ledwozyw A, Kadziołka A (1989) Ontogenesis of antioxidant enzymes in swine. Pol Arch Weter 29: 77-94.

8. Snityns'kyĭ VV, Antoniak HL, Bershads'kyı̆ VI (1996) The age-related changes in the antioxidant system enzymes of the erythroid cells of swine at the early stages of postnatal development. Fiziol Zh 42: 19-25

9. Drackley JK (1999) ADSA Foundation Scholar Award. Biology of dairy cows during the transition period: the final frontier? J Dairy Sci 82: 2259-2273.
10. National Research Council (2001) Nutrient requirements of Dairy Cattle $\left(7^{\text {th }}\right.$ Edn), National Academy Press, Washington DC, USA.

11. Neuwirth JG, Norton JK, Rawlings CA, Thompson FN, Ware GO (1979) Physiologic responses of dairy calves to environmental heat stress. Int $J$ Biometeorol 23: 243-254.

12. Gebremedhin KG, Cramer CO, Porter WP (1981) Predictions and measurements of heat production and food and water requirements of Holstein calves in different environments. Trans Am Soc Agric Eng 24: 715-720.

13. Heinrichs AJ, Heinrichs BS, Harel O, Rogers GW, Place NT (2005) A prospective study of calf factors affecting age, body size, and body condition score at first calving of holstein dairy heifers. J Dairy Sci 88: 2828-2835.

14. Toft N, Houe H, Nielsen SS (2004) Sample size and sampling methods. In Houe $\mathrm{H}$, Ersbøll AK, Toft N (Eds), Introduction to veterinary epidemiology. Simon and Schuster, New York, NY, USA.

15. Ingraham RH, Stanley RW, Wagner WC (1979) Seasonal effects of tropical climate on shaded and nonshaded cows as measured by rectal temperature adrenal cortex hormones, thyroid hormone, and milk production. Am J Vet Res 40: $1792-1797$. 